\title{
Estradiol in the Preoptic Area Regulates the Dopaminergic Response to Cocaine in the Nucleus Accumbens
}

\author{
Daniel J Tobiansky', Ryan G Will',2, Kevin D Lominac',2, Jonathan M Turner ${ }^{3}$, Tomoko Hattori', \\ Krittika Krishnan', Julia R Martz', Victoria L Nutsch ${ }^{3}$ and Juan M Dominguez ${ }^{*, 1,2,3}$ \\ 'Department of Psychology, The University of Texas at Austin, Austin, TX, USA; 'Waggoner Center for Alcohol and Addiction Research, \\ The University of Texas at Austin, Austin, TX, USA; ${ }^{3}$ Institute for Neuroscience, The University of Texas at Austin, Austin, TX, USA
}

\begin{abstract}
The sex-steroid hormone estradiol (E2) enhances the psychoactive effects of cocaine, as evidenced by clinical and preclinical studies. The medial preoptic area (mPOA), a region in the hypothalamus, is a primary neural locus for neuroendocrine integration, containing one of the richest concentrations of estrogen receptors in the CNS and also has a key role in the regulation of naturally rewarding behaviors. However, whether estradiol enhances the neurochemical response to cocaine by acting in the mPOA is still unclear. Using neurotoxic lesions and microdialysis, we examined whether the mPOA modulates cocaine-induced neurochemical activity in the nucleus accumbens. Tract tracing and immunohistochemical staining were used to determine whether projections from the mPOA to the ventral tegmental area (VTA) are sensitive to estrogen signaling. Finally, estradiol microinjections followed by microdialysis were used to determine whether estrogenic signaling in the MPOA modulates cocaine-induced changes of dopamine in the nucleus accumbens. Results showed that lesions of the mPOA or microinjections of estradiol directly into the mPOA increased cocaine-induced release of dopamine in the nucleus accumbens. Immunohistochemical analyses revealed that the mPOA modulates cocaine responsiveness via projections to both dopaminergic and GABAergic neurons in the VTA, and that these projections are sensitive to estrogenic stimulation. Taken together, these findings point to a novel estradiol-dependent pathway that modulates cocaine-induced neurochemical activity in the mesolimbic system. Neuropsychopharmacology (2016) 4I, I897-1906; doi: 10.1038/npp.2015.360; published online 6 January 2016
\end{abstract}

\section{INTRODUCTION}

The sex-steroid hormone estradiol (E2) enhances the psychoactive effects of cocaine, as evidenced by clinical and preclinical studies (Carroll et al, 2004; Festa and Quinones-Jenab, 2004). Women self-report lower cocaine cravings during the luteal phase of the menstrual cycle, when progesterone is high, and they self-report relatively greater cravings during the follicular phase, when estrogen is rising and progesterone is low (Evans and Foltin, 2010). Rodent studies point to a similar steroid-dependent effect. Female rats self-administer more cocaine and reach a higher break point during the estrus phase of their cycle than in the proestrus or diestrus phase (Roberts et al, 1989). Congruently, E2 replacement restores the rate of cocaine selfadministration in rats that exhibited decreased responding following ovariectomies (Hu et al, 2004). Although E2 clearly looks to increase the incentive value of cocaine reinforcement by acting in the mesolimbic reward system, whether regions outside of the mesolimbic system also mediate this increased response is still not clear.

\footnotetext{
*Correspondence: Professor JM Dominguez, Department of Psychology, The University of Texas at Austin, 108 E Dean Keeton, Mail Stop A8000, Austin, TX 787|2-I043, USA, Tel: +I 512232 8050, Fax: + 512 47| 6175, E-mail: dominguez@utexas.edu

Received 16 August 2015; revised I December 2015; accepted I December 2015; accepted article preview online 9 December 2015
}

The medial preoptic area (mPOA) lies just rostral to the anterior hypothalamus and caudal to the diagonal band of Broca. It is the most extensively studied brain region relating to the regulation of maternal and sexual behaviors, in part, because it is also a primary neural locus for the integration of endocrine stimulation. It contains one of the highest concentrations of cells expressing sex-steroid hormone receptors, including but not limited to estrogen receptor- $\alpha$ $(\mathrm{ER} \alpha)$, progesterone receptors (PR), and membrane-bound G-protein estrogen receptors (GPERs) (Brailoiu et al, 2007; Lauber et al, 1991). By virtue of its role as a center of neuroendocrine activity, the mPOA receives steroid hormone stimulation that aids in the regulation of maternal (Lonstein et al, 2015; Stolzenberg and Numan, 2011) and sexual behaviors (Graham and Pfaus, 2013; Pfaus et al, 2015). Given its role in these behaviors, it is also not surprising that the $\mathrm{mPOA}$ has robust anatomical interactions with brain pathways regulating reward response. Namely, the mPOA reciprocally innervates the mesolimbic dopamine (DA) system, particularly the ventral tegmental area (VTA) (Ikemoto, 2007; Simerly and Swanson, 1988), to modulate reward (Numan and Smith, 1984).

With its sensitivity to E2, its role in natural reward, and its robust anatomical interactions with the mesolimbic system, the mPOA is a logical neural locus in which estradiol should act to modulate cocaine response, yet little is known about the effects of $\mathrm{E} 2$ in the mPOA on cocaine response. To this 
end, we used a female rat model to determine (1) whether the mPOA modulates cocaine-induced DA release in the nucleus accumbens (NAc) (2) whether mPOA-VTA efferents are sensitive to sex-steroid hormones, and (3) whether E2 acts in the $\mathrm{mPOA}$ to modulate cocaine-induced DA activity in the NAc.

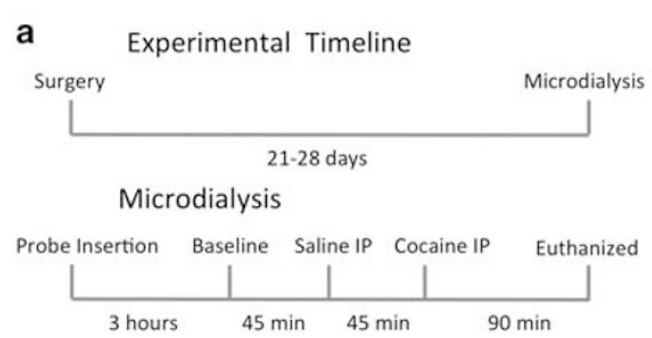

c

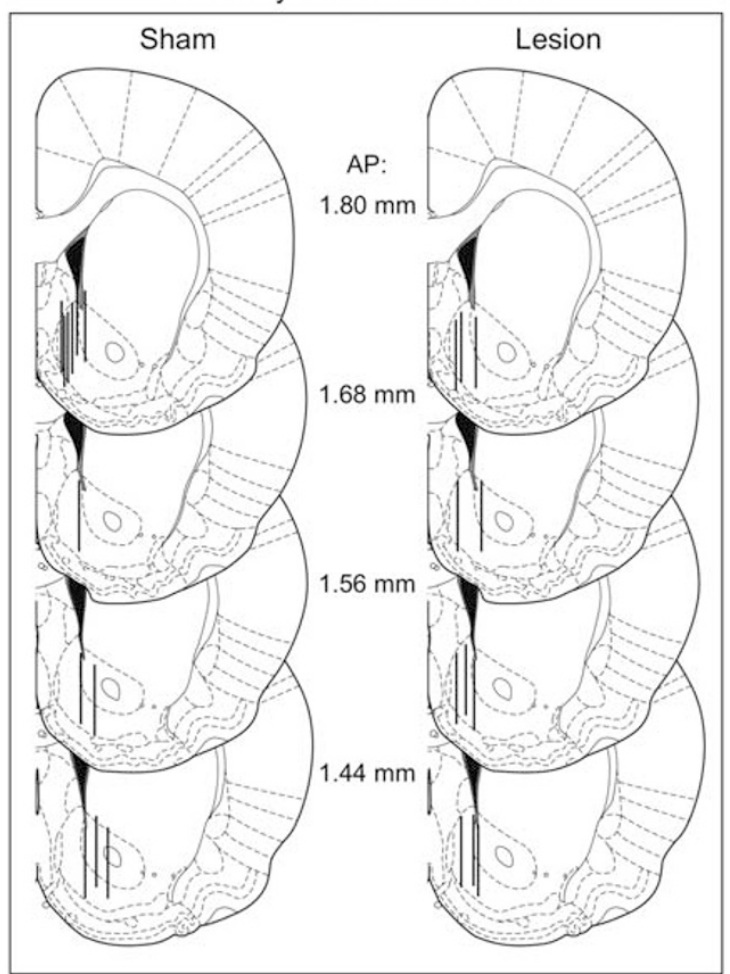

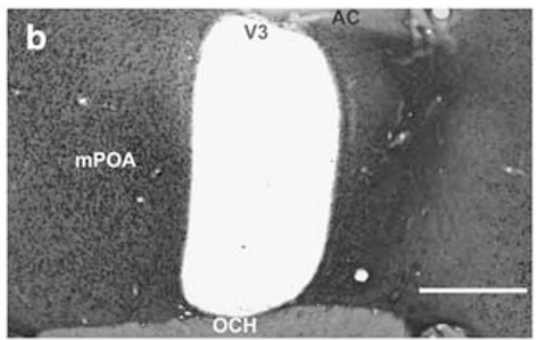

d NMDA Lesions
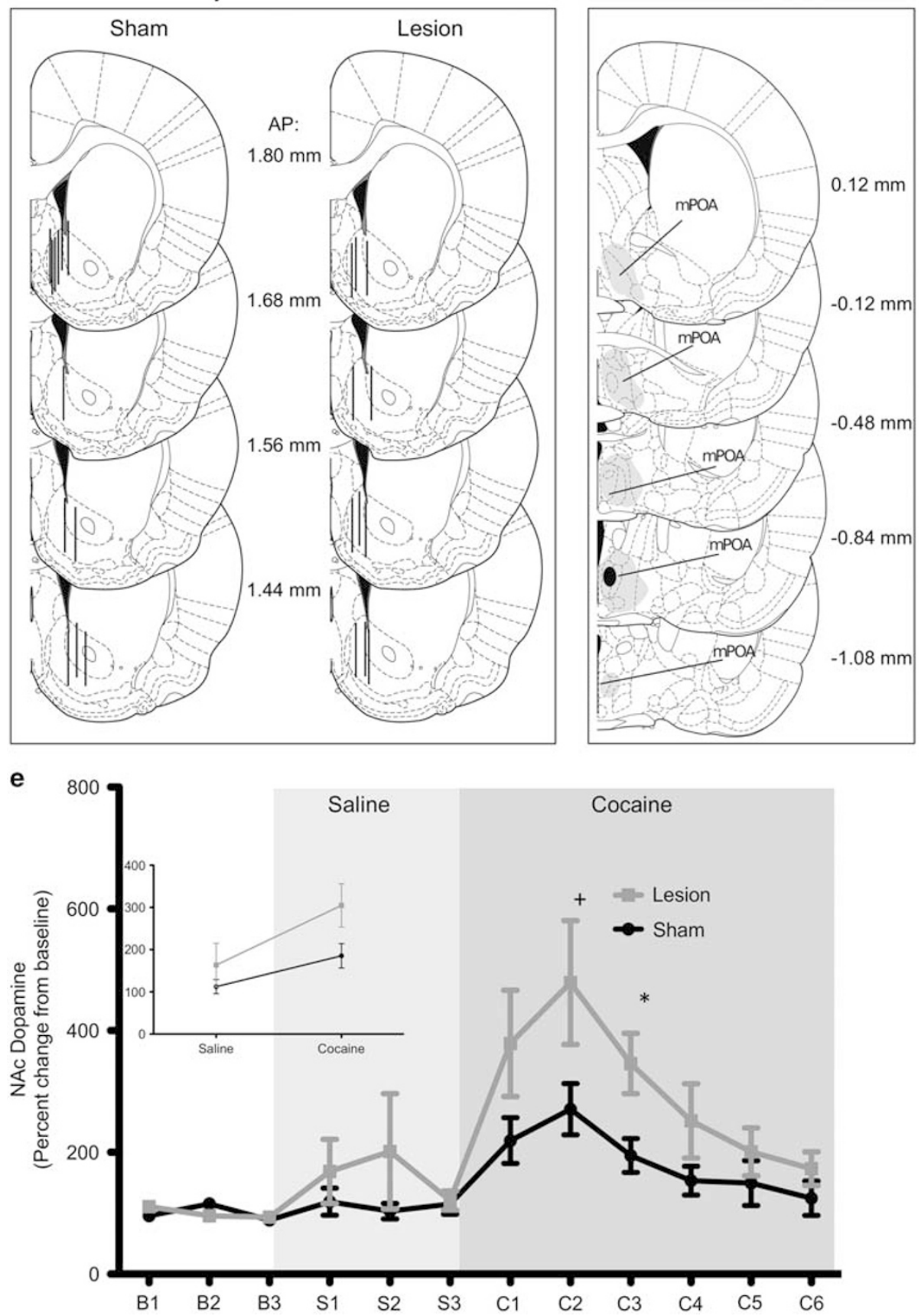


\section{MATERIALS AND METHODS}

See Supplementary Methods for a complete description of methodology and statistical analysis.

\section{Subjects}

Adult female Sprague-Dawley rats (PN 65-74, 200-224 g; Harlan Laboratories, Indianapolis, IN) were double housed in a temperature-controlled room $\left(22^{\circ} \mathrm{C}, 30-70 \%\right.$ humidity $)$ on a reverse light/dark cycle ( $12 \mathrm{~h}$ light/12 h dark; lights off at 1000 hours), and food and water were freely available. All experiments were approved by the Institutional Animal Care and Use Committee at The University of Texas at Austin and were in accordance with the National Institutes of Health Guidelines for the Use of Animals in Research.

\section{Procedural Relationship}

Experiment 1: $m P O A$ lesions and NAc microdialysis for $D A$. To determine whether the mPOA modulates cocaineinduced DA release in the NAc, female rats $(n=30$; sham $n=15$, lesion $n=15$ ) received $N$-methyl-D-aspartate lesions of the mPOA, cannulation above the NAc shell-core border, and ovariectomies plus chronic systemic E2 replacement to control for E2-mediated DA release (Cummings et al, 2014). Once animals recovered from surgery (2-3 weeks), the microdialysis probes were inserted and all subjects received an injection of saline $(1 \mathrm{ml} / \mathrm{kg}$, intraperitoneally) followed by an injection of cocaine $(10 \mathrm{mg} / \mathrm{kg}$, intraperitoneally). Animals were then killed and probe and lesion placement were assessed with methyl green and NeuN staining, respectively (Figure 1a).

Experiment 2: $m P O A$ to VTA projections. A set of 16 female rats were ovariectomized, received iontophoretic injections of fluorogold (FLG) into the VTA, plus chronic systemic E2 replacement. Ten days after FLG injection, these subjects were killed and their brains collected to examine the presence of sex-steroid hormone receptors in mPOA neurons projecting to the VTA. FLG-positive cells were colocalized with ER $\alpha$, PR, and GPER, a membrane-bound estrogen receptor involved in fast non-genomic signaling of estrogen (Brailoiu et al, 2007). A second set of females $(n=6)$ received biotinylated dextran amine (BDA) and FLG injections into the mPOA and NAc, respectively, along with ovariectomies plus E2 replacement. Ten days after injections, these subjects were killed and their brains were removed. Figure $2 \mathrm{a}$ and $\mathrm{b}$ provide an experimental timeline.
Experiment 3: $m P O A$ microinjections of E2 and NAc microdialysis for DA. To determine whether E2 in the mPOA modulates cocaine-induced DA in the NAc, a group of 32 females were ovariectomized and then received cannulation of the mPOA and NAc core-shell border. Because we were interested in the role of $\mathrm{E} 2$ in the mPOA, animals did not receive chronic systemic E2 replacement. One group received systemic E2 injections $(n=16) 9$ days and 5 days before microdialysis to mimic estrogen surges in a naturally cycling female, whereas a second group received vehicle $(n=16)$ during these days and were without systemic E2 for $~ 3.5$ weeks before microdialysis. One day before microdialysis, animals were microinjected with E2 $(n=16)$ or artificial cerebrospinal fluid (aCSF) $(n=16)$ into the mPOA. Hormone pretreatment and hormone microinjection were performed with a balanced $2 \times 2$ design. Microdialysis and probe placement were performed as described in the Supplementary Methods. Figure $3 \mathrm{a}$ provides an experimental timeline

\section{RESULTS}

\section{Lesions of the mPOA Facilitate Cocaine-Induced DA Release in the NAc}

All animals included in the data analyses were checked for lesion placement (Figure 1d). Histological analysis of lesions revealed that 9 of 15 were successful. Of these nine lesions, most were localized in the central mPOA. There was no significant difference $\left(t_{(15)}=0.40, p=0.69\right)$ in probe recovery between probes used in the sham lesion $(17.18 \pm 4.99 \%)$ and lesion $(20.09 \pm 4.83 \%)$ groups. Additionally, microdialysis probes were all placed in the NAc, with $50 \%$ placement in the shell region of the NAc, $41 \%$ in the shell-core border, and $9 \%$ in the core (Figure 1c). There were no regional differences in average percent change in DA in response to either saline $\left(\mathrm{F}_{(2,18)}=0.54, p=0.59\right)$ or cocaine $\left(\mathrm{F}_{(2,18)}=0.27, p=0.77\right)$.

Analysis of DA in the NAc with mixed-effects regression revealed a significant time $\times$ lesion interaction $\left(\mathrm{F}_{(1,164)}=5.74\right.$, $p<0.05)$ as well as a significant drug $\times$ lesion interaction $\left(\mathrm{F}_{(1,164)}=8.71, p<0.01\right.$; Figure 1e). Decomposition of the drug $\times$ lesion interaction revealed that lesioned subjects exhibited a more robust increase in cocaine-induced DA release (lesion vs sham: $304.84 \pm 41.12$ vs $199.53 \pm 54.40$; $\left.t_{(19)}=-2.0, p=0.057\right)$, but there was no lesion difference in response to saline (percent change in lesion vs sham: $163.66 \pm 36.19$ vs $\left.121.01 \pm 47.89 ; \quad t_{(19)}=-0.92, p=0.37\right)$. For both sham- $\left(t_{(95)}=-4.76, \quad p<0.001\right)$ and lesion$\left(t_{(71)}=-3.34, p<0.01\right)$ treated subjects, NAc DA was higher in response to cocaine compared with saline. Decomposition of the time $\times$ lesion interaction revealed there was not a

Figure I (a) Experimental timeline for microdialysis experiment, examining the effects of neurotoxic lesions in the medial preoptic area (mPOA) on cocaine-induced release of dopamine (DA) in the nucleus accumbens (NAc). (b) Representative micrograph depicting unilateral lesions of the mPOA, lesion side is on the right and intact side is on the left of the picture. Lesions were verified using staining for NeuN, a neuronal nuclear antigen (scale bar is $500 \mu$ m; AC, anterior commissure; $\mathrm{OCH}$, optic chiasm; $\mathrm{V} 3$, third ventricle). Representations of histological analyses of probe placement and lesions are depicted in panels $\mathrm{c}$ and d. (c) Coronal hemisections through the right side of the NAc ( $.44-1.80 \mathrm{~mm}$ anterior to the bregma). Lines represent placement of microdialysis probe in sham- and N-methyl-D-aspartate (NMDA)-lesioned animals. (d) Coronal hemisections through the mPOA (0.12 mm anterior to I.08 mm posterior to the bregma). The largest acceptable lesions (shaded area) and smallest lesions (solid area) are shown, adapted from Paxinos et al (2007). (e) Graph summarizing results showing that $\mathrm{mPOA}$ lesions enhance cocaine-induced DA release. DA release changes in percent from baseline between sham-lesioned $(n=12)$ and lesioned $(n=9)$ female rats. Inset shows significant interaction $\left(t_{(164)}=2.94, p<0.01\right)$ between lesion and drug (saline and cocaine) collapsed across time. Values are expressed as mean \pm SEM. Differences between sham and lesioned subject: $*<0.05 ;+=0.07$. I.p., intraperitoneally. 
significant effect of time for either lesion $\left(\mathrm{F}_{(1,71)}=0.24\right.$, $p=0.62)$ or sham lesioned $\left(\mathrm{F}_{(1,95)}=1.27, p=0.26\right)$ subjects. This finding is not surprising given the quadratic nature of percent change DA in response to cocaine and that mixedeffects regression treats time as a continuous variable and not a factor. When time is held constant, however, lesioned subjects had a greater percent increase in DA $30 \mathrm{~min}$ $\left(t_{(19)}=1.89, p=0.07\right)$ and $45 \min \left(t_{(19)}=2.62, p<0.05\right)$ after cocaine administration, although some of these time points do not reach the significance threshold. Finally, it is worth noting that one lesion subject had an abnormally high increase in percent DA $30 \mathrm{~min}$ after saline injection (20.84 SDs above the mean with this observation excluded). However, DA concentrations from this subject were not radically different from other subjects in the lesion group at all other time points and cocaine administration increased a

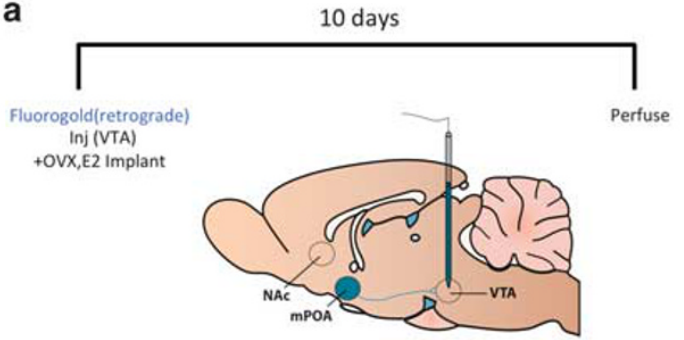

b

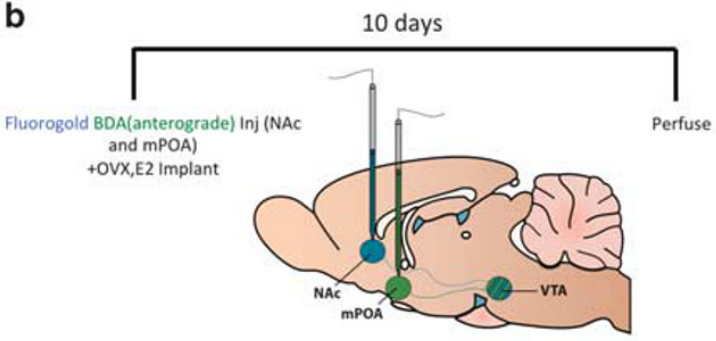

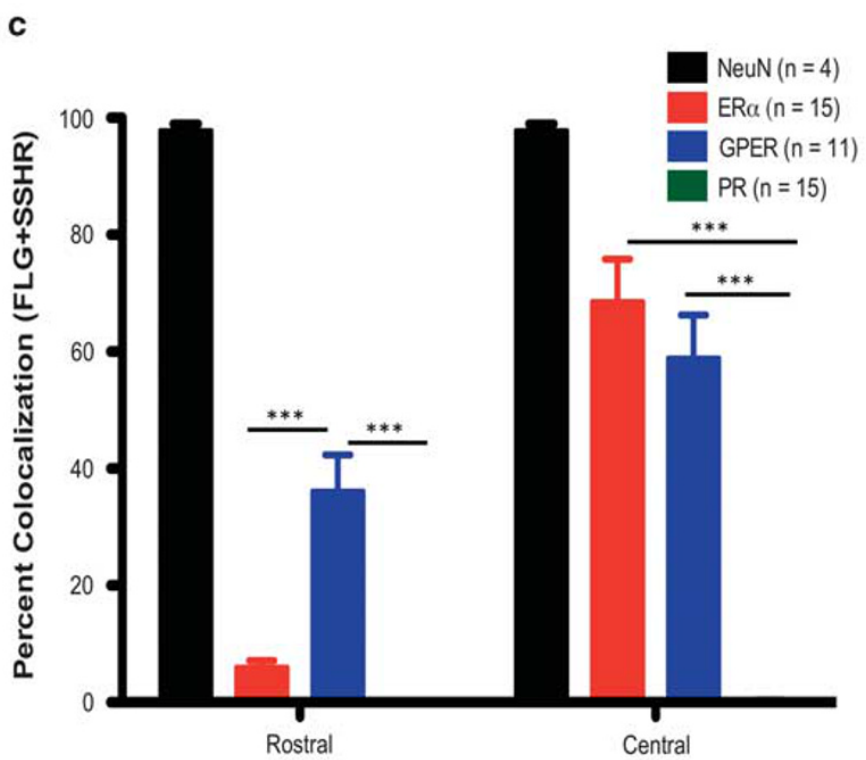
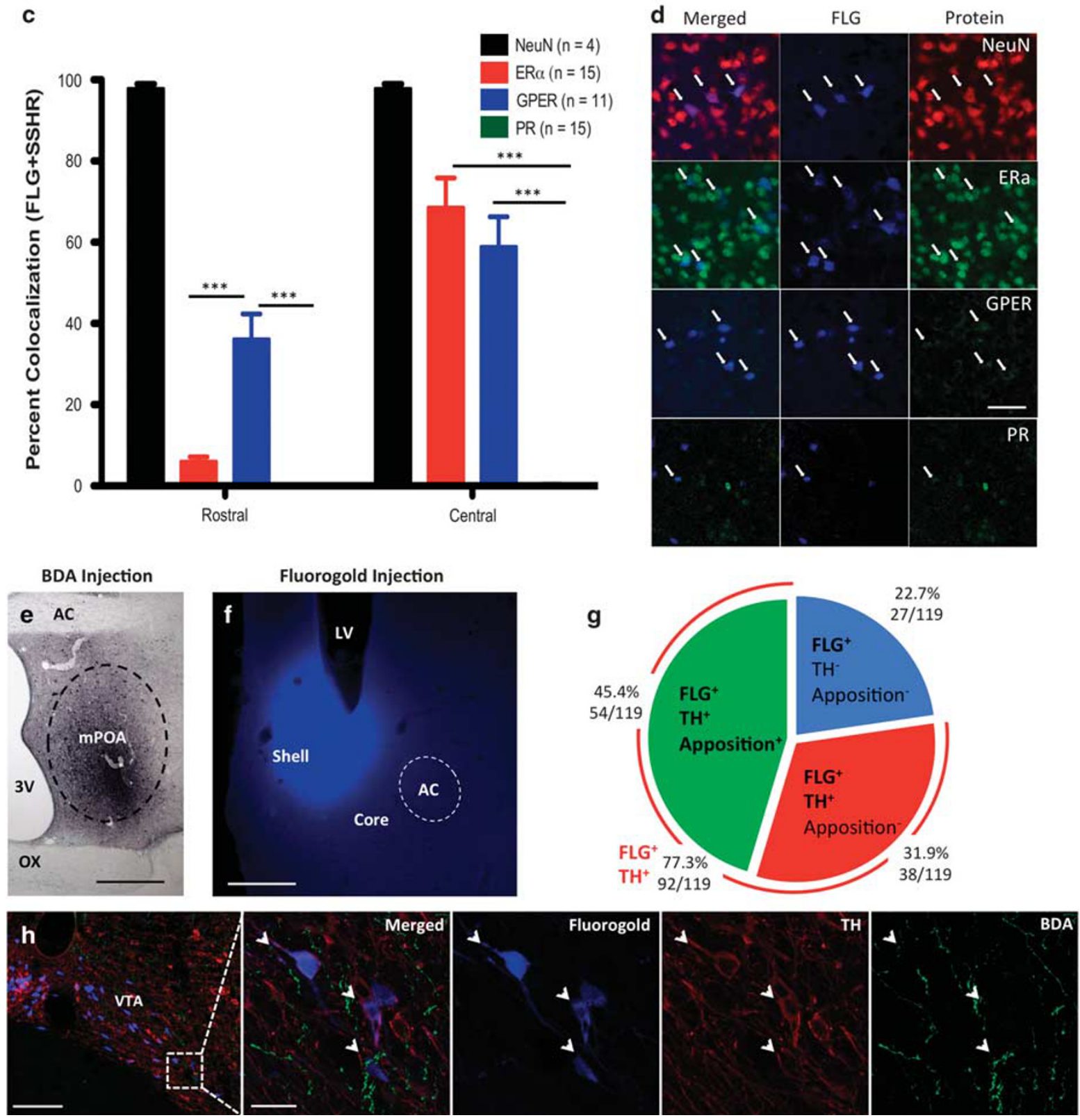
NAc DA by $\sim 395 \%$ relative to the prior saline time point. Thus, we decided to retain all data from this subject rather than exclude the animal. In summary, lesions of the mPOA increase DA levels in response to cocaine but not saline ipsilaterally to the lesion site.

\section{Efferents to the VTA from the mPOA are Constrained to Rostral and Central Subregions}

As previously reported by our lab (Tobiansky et al, 2013), the rostral and central mPOA (mPOAr and mPOAc, respectively) contain the majority of neurons projecting to the VTA. Using a repeated-measures one-way ANOVA, we found a statistically significant main effect of region within animals $\left(\mathrm{F}_{(2,28)}=53.53 ; p<0.001\right)$. In particular, the central region $(102.83 \pm 12.65)$ had significantly more FLG-positive neurons than the rostral region $(43.6 \pm 6.02 ; p<0.001)$, which in turn had significantly more FLG-positive neurons than the caudal region $(1.03 \pm 0.16 ; p<0.001)$. As the rostral and central subregions of the mPOA contained the vast majority of VTA efferents, all subsequent analyses focused on the colocalization of FLG and sex-steroid hormone receptors in these subregions.

\section{Projections from the mPOA to the VTA Contain Ovarian Hormone Receptors}

Nearly all mPOA-VTA efferents in a randomly selected subset of animals were immunopositive for NeuN $(97.80 \pm 1.5 \% ; n=4)$. There was also a significant interaction between mPOA subregions and the percent of colocalized sex-steroid hormone receptors $\left(\mathrm{F}_{(2,36)}=23.73 ; p<0.001\right)$. Colocalization of nuclear sex-steroid hormone receptors were seen in disparate quantities, with $\mathrm{ER} \alpha(5.98 \pm 1.15 \%$ in the mPOAr and $68.57 \pm 7.23 \%$ in the mPOAc) being the higher of the two, whereas there was a near absence of PR ( $<1 \%$ in both the mPOAr and mPOAc). Absence of PR colocalization with FLG+ cells may be explained by their tendency to be more medially located in the mPOAc (Lauber et al, 1991), whereas the FLG-positive neurons were located in the central and lateral aspects of the mPOAc. Additionally, GPER was present in at least 36\% of the efferents (GPER: $36.10 \pm 6.25 \%$ in the mPOAr and $58.86 \pm 7.38 \%$ in the mPOAc). A summary of these results is given in Figure $2 \mathrm{c}$ and $\mathrm{d}$.

\section{mPOA Efferents to the VTA Appose Tyrosine Hydroxylase-Containing Cells that Project to the NAc}

Cells in the mPOA project to the VTA, but the specific downstream targets of these efferent fibers have not been definitively identified. Consistent with previous studies (Ikemoto, 2007), the vast majority of cells in the VTA that project to the NAc were dopaminergic (ie, tyrosine hydroxylase (TH)-ir; 77.3\%). Here we discovered that of the VTA projections to the NAc, $45.4 \%$ were apposed by mPOA efferents and $41.3 \%$ of the VTA cells apposed by mPOA efferents contained TH-ir. A moderate percentage (45.6\%) of the TH-ir cells in the VTA, regardless of the area they project to, were apposed by fibers originating from cells in the mPOA. All cells and apposition percentages were quantified ipsilaterally to the site of tract tracer injections. See Figure $2 \mathrm{e}-\mathrm{g}$ for a summary of these results.

\section{E2 Microinjections into the mPOA Enhance Cocaine-Induced DA Release in the NAc}

Microinjection and microdialysis-probe placement were histologically verified for all subjects (Figure $3 \mathrm{~b}$ and $\mathrm{c}$ ). Twenty-six of 31 microinjections were located in the $\mathrm{mPOA}$; however, two of these animals contained visibly infected brain tissue and were excluded. Additionally, one subject had a moderately sized lesion in the mPOA and was excluded. Interestingly, this subject had a greater percent increase in DA in response to cocaine than most other subjects; however, direct comparison with the previous lesion study would be unwarranted. Microdialysis probes were all placed in the NAc, with the majority $(47.8 \%)$ in the shell region of the NAc, $43.5 \%$ in the shell-core border, and $8.7 \%$ in the core. There were no regional differences in average percent change in $\mathrm{DA}$ in response to either saline $\left(\mathrm{F}_{(2,20)}=0.26\right.$, $p=0.77)$ or cocaine $\left(\mathrm{F}_{(2,20)}=0.06, p=0.94\right)$. A four-way mixed ANOVA was used to examine the effects of hormone pretreatment, drug, E2 microinjection, and time on percent change in NAc DA. There was no significant four-way interaction $\left(\mathrm{F}_{(3,133)}=2.03, p=0.11\right)$. However, there was a significant three-way interaction and several two-way interactions present in the saturated model. These interactions were subsequently interpreted using models lacking higher order interactions.

A mixed ANOVA, excluding the fourth-order term, revealed that the only significant third-order interaction was between hormone pretreatment, drug, and time

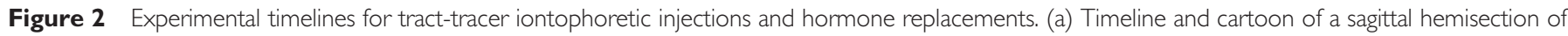

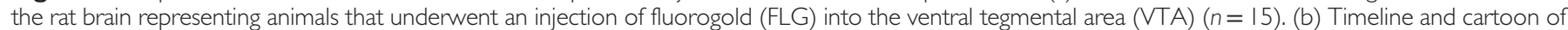

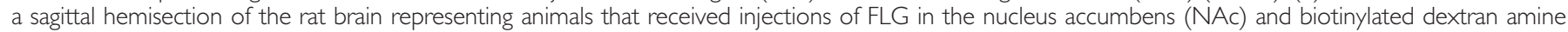

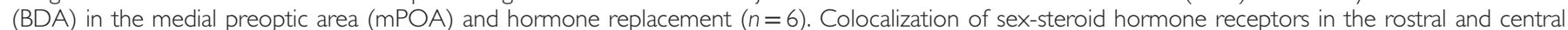

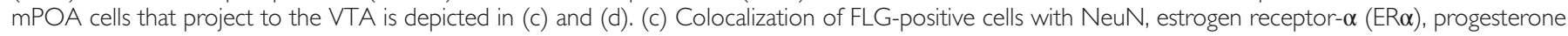

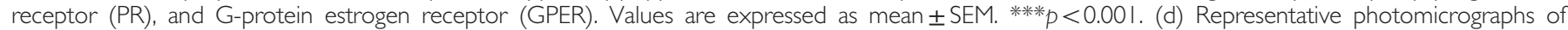

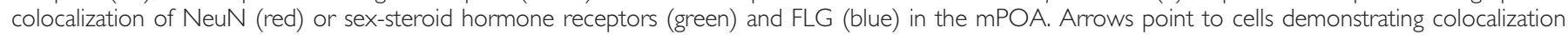

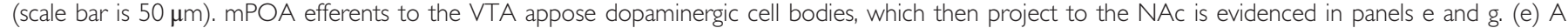

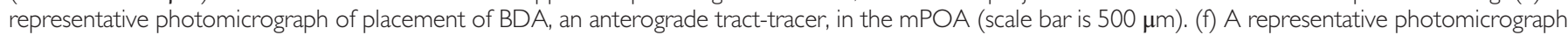

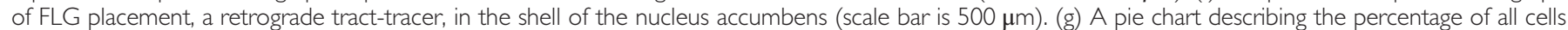

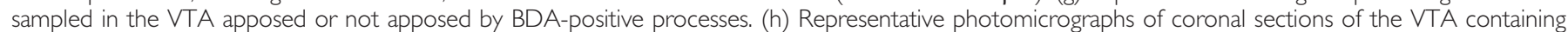

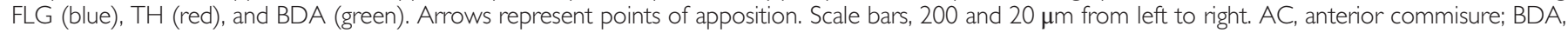
biotinylated dextran amine; LV, lateral ventricle; $\mathrm{OX}$, optic chiasm; TH, tyrosine hydroxylase; 3V, third ventricle.
} 
$\left(F_{(3,136)}=3.83, p<0.05\right.$; Figure 3d). Decomposition of this interaction revealed that there were no two-way interactions between hormone pretreatment and drug at any of the four time points. There was an interaction between time and hormone pretreatment in response to cocaine $\left(\mathrm{F}_{(3,63)}=5.14\right.$, $p<0.01)$ but not saline $\left(\mathrm{F}_{(3,63)}=0.72, p=0.54\right)$. Furthermore, there was a significant drug $\times$ time interaction $\left(\mathrm{F}_{(3,77)}=6.40\right.$, $p<0.001)$ for subjects pretreated with $\mathrm{E} 2$ and a marginal effect for subjects pretreated with vehicle $\left(\mathrm{F}_{(3,70)}=2.30\right.$, $p=0.08)$. Decomposition of the drug $\times$ time interaction

a E2 pretreatment

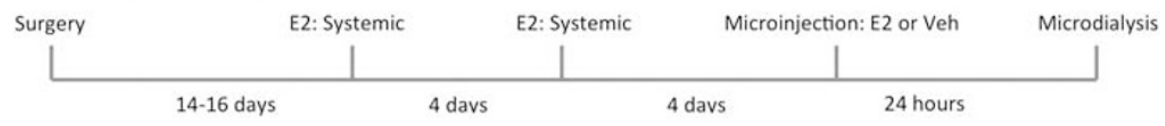

Veh pretreatment

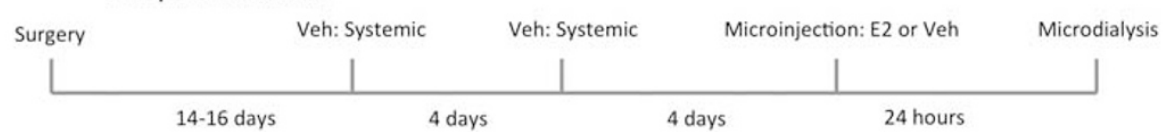

b

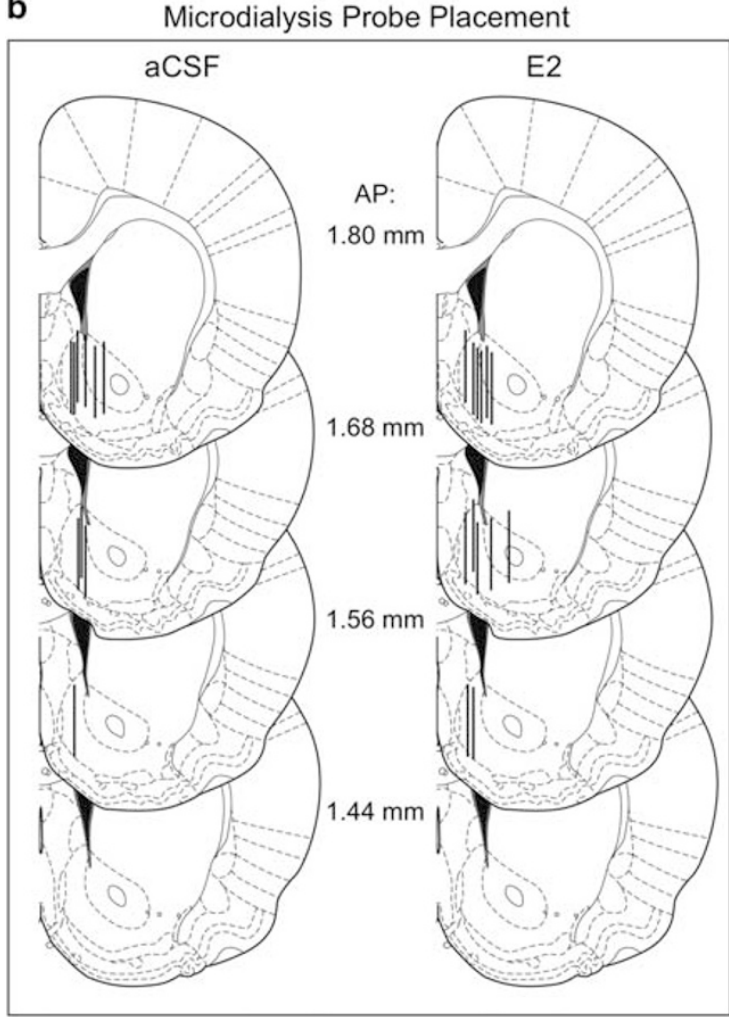

C

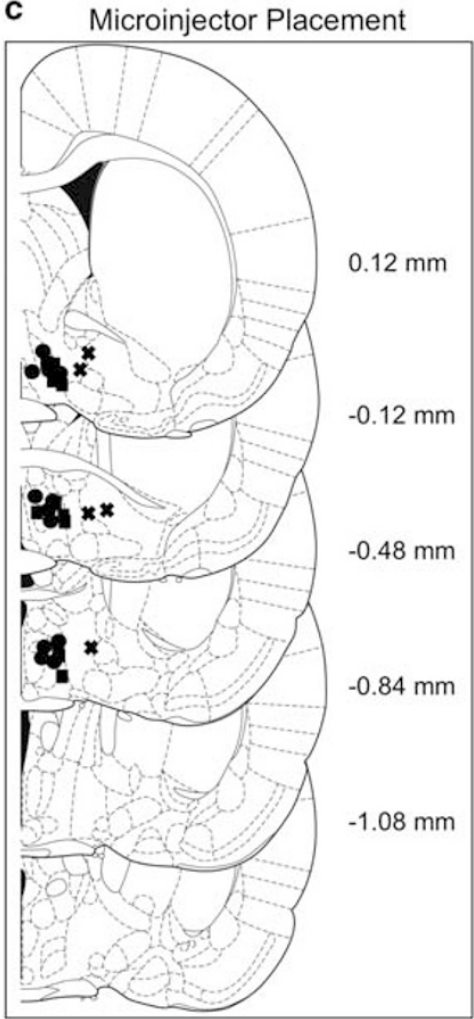

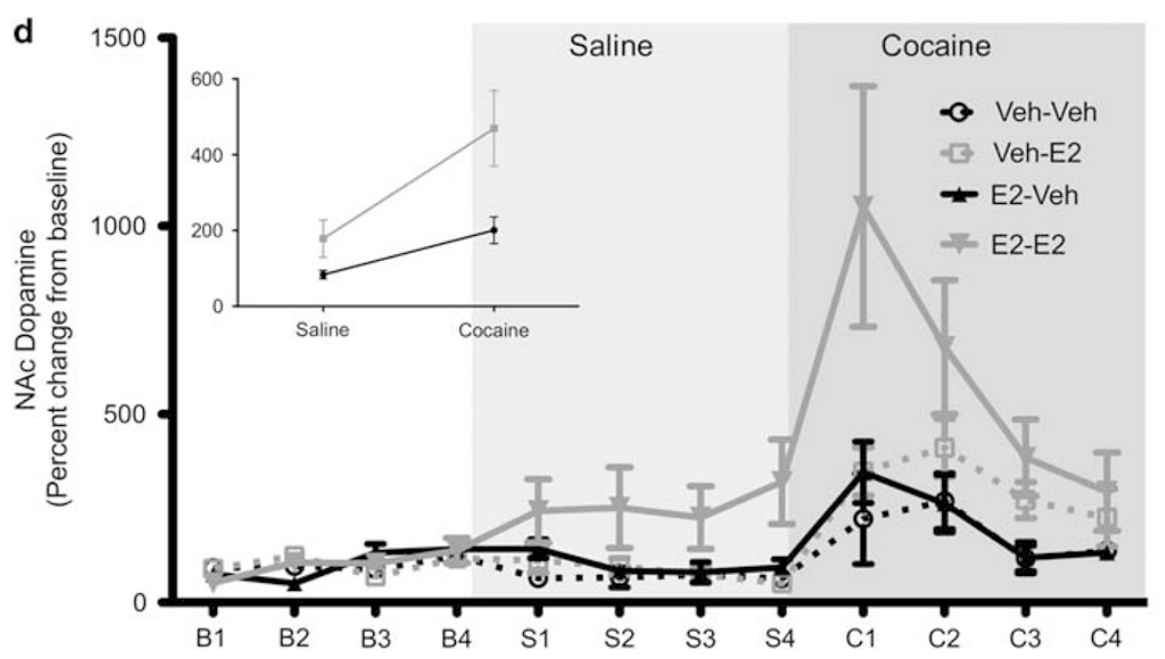


revealed that E2 pretreatment modulated the time course of DA response to cocaine but not saline. Specifically, post hoc tests revealed that the percent change in DA was greater 15 min after cocaine administration compared with 45 min $(z=-4.47, p<0.001)$ and $60 \min (z=-4.91, p<0.001)$ after cocaine administration for subjects who received E2 pretreatment leading up to microdialysis. These results are recapitulated by the hormone treatment $\times$ time interaction described above.

There was also a significant drug $\times \mathrm{E} 2$ microinjection interaction $\left(\mathrm{F}_{(1,21)}=4.71, p<0.05\right)$, whereas neither the hormone pretreatment $\times$ drug $\left(\mathrm{F}_{(1,20)}=0.58, p=0.46\right)$ nor the hormone pretreatment $\times \mathrm{E} 2$ microinjection $\left(\mathrm{F}_{(1,19)}=1.64\right.$, $p=0.21)$ interactions were significant. All other significant second-order interactions included the time factor and were non-orthogonal to the results described above. Decomposition of this interaction revealed that, in response to cocaine, E2-treated animals exhibited a greater percent increase in DA- than vehicle-treated animals $\left(t_{(21)}=2.26, p<0.05\right.$; $469.2 \pm 100.0$ vs $200.76 \pm 36.7)$, but there was no effect of E2 microinjection in response to saline $\left(t_{(21)}=1.65, p=0.12\right.$; $178.48 \pm 49.4$ vs $83.54 \pm 12.8)$. Compared with saline, cocaine increased the percent change in DA for both E2- $\left(t_{(11)}=4.45\right.$, $p<0.001)$ and vehicle- $\left(t_{(9)}=3.60, p<0.01\right)$ treated animals.

Visual examination of the data also suggested that combination of E2 pretreatment and an E2 microinjection facilitated cocaine-induced DA in the NAc, specifically at $\mathrm{C} 1$ in Figure 3d. However, as noted above, there were no four-way interactions. Tukey corrected comparisons of between-group differences at the eight time points revealed no significant differences between subjects in E2 pretreatment/E2 microinjection group and the other three groups at time point $\mathrm{C} 1$. However, there were notable trend differences between several groups: E2/E2 vs Veh/Veh $(p=0.0503)$ and E2/E2 vs E2 pretreatment/Veh microinjection $(p=0.0906)$.

\section{DISCUSSION}

Here we demonstrated that the mPOA modulates dopaminergic response to cocaine in the NAc. Specifically, our experiments showed that lesions of the mPOA facilitate cocaine-induced DA release in the NAc. Because the major source of DA to the NAc is the VTA, we then analyzed mPOA-VTA interactions and found that efferents to the VTA from the mPOA are both constrained to rostral and central subregions and are also responsive to E2, as evidenced by the presence of $\operatorname{ER} \alpha$ and GPER in these cells.
With regard to the downstream targets of these cells, we discovered that a large number of them apposed $\mathrm{TH}$ positive cells in the VTA, which then also project to the NAc. These findings pointed to possible influences of E2 in the mPOA on mesolimbic DA activity. To this end, we then determined that E2 microinjections into the mPOA indeed enhance cocaine-induced release of DA in the NAc. Taken together, these data suggest that $\mathrm{E} 2$ in the mPOA facilitates cocaine-induced DA activity in the mesolimbic system.

Although the majority of evidence points to the mesolimbic DA system as a necessary neurobiological end point when describing cocaine's effects, this system does not operate in isolation, and in fact input from other structures may have a significant role in cocaine-induced activity. Indeed, here we provide evidence describing a novel estradiol-dependent input into the mesolimbic system that modulates cocaine-induced neurochemical activity, likely via $\gamma$-aminobutyric acid (GABA) input, as suggested previously (Tobiansky et al, 2013). Our findings demonstrate that neurotoxic lesions of the mPOA increased cocaine-induced DA release in the NAc, that many of the neurons projecting from the mPOA to the VTA are sensitive to E2, and that E2 microinjections into the mPOA $24 \mathrm{~h}$ before cocaine administration increased cocaine-induced DA release in the NAc. These results are in line with earlier work from our laboratory, demonstrating that lesions of the mPOA enhanced cocaine-induced conditioned place preference and cocaine-induced neural activity in the NAc (Tobiansky et al, 2013).

With this evidence in hand, we postulate that the mechanism through which the mPOA regulates cocaine neurobiological response is via its projections to the mesolimbic system, particularly inhibitory projections to the VTA. Although it is true that the mPOA contains few efferents directly to the NAc (Simerly and Swanson, 1988), it does nevertheless contain strong reciprocal connections with the VTA (Miller and Lonstein, 2009), suggesting indirect regulation of NAc DA via the VTA. These projections from the mPOA to the VTA are at least partly inhibitory, as the primary amino acid produced by preoptic neurons is GABA (Herbison et al, 1992). Although it is possible that some projections are also glutamatergic, these are likely far fewer than GABAergic since cells containing glutamate decarboxylase (GAD), the enzyme that catalyzes the synthesis of GABA, are more prevalent than glutamate-producing cells in the mPOA (Tsuneoka et al, 2013). Expression of genes that encode GAD are also highly expressed in the mPOA (McHenry et al, 2015). Maternal behavior increases Fos-ir of GABA-producing cells in the mPOA of virgin (Tsuneoka

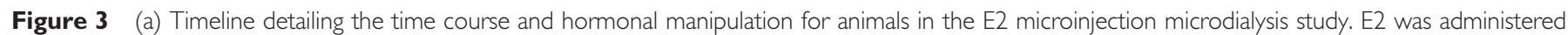

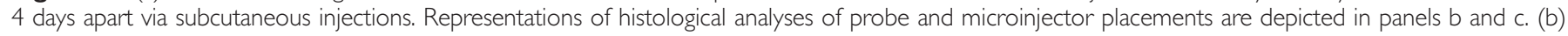

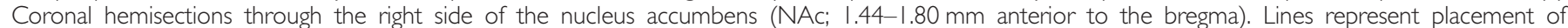

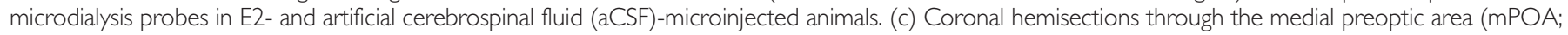

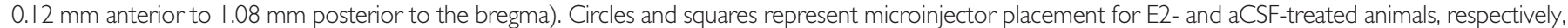

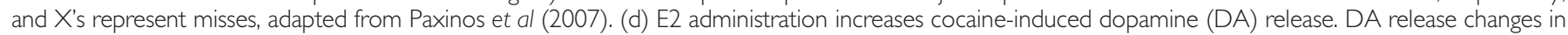

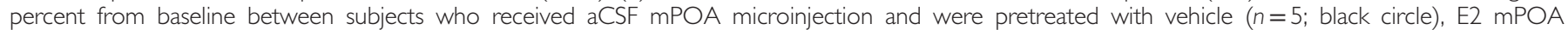

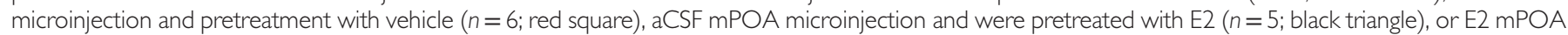

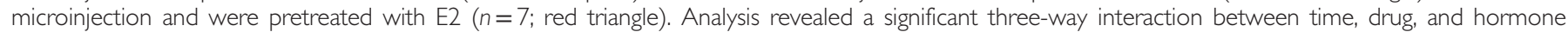

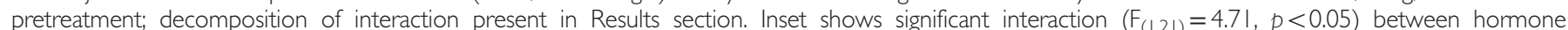

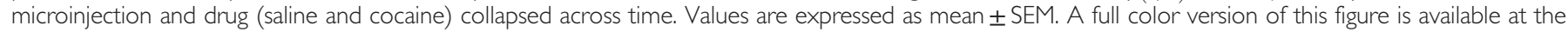
Neuropsychopharmacology journal online. 


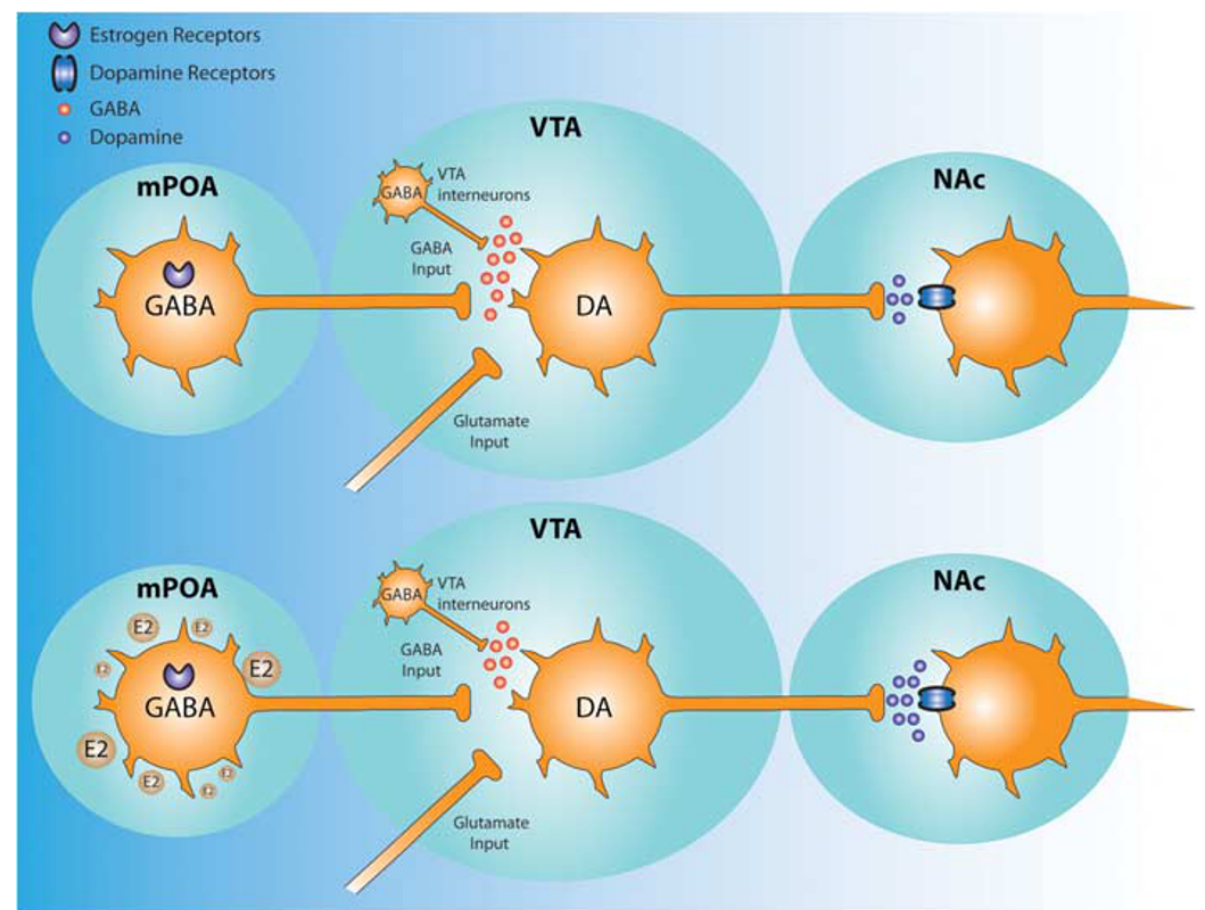

Figure 4 Hypothetical model linking estradiol in the medial preoptic area (mPOA) with increased levels of dopamine (DA) in the nucleus accumbens (NAc) following cocaine administration. (Top) Combined with $\gamma$-aminobutyric acid (GABA) from ventral tegmental area (VTA) interneurons, mPOA-VTA GABA efferents maintain tonic inhibition on DA-producing neurons in the VTA. With this inhibition, lower levels of DA are present in the NAc, after cocaine administration. (Bottom) However, with increased E2 stimulation of neurons in the mPOA, GABAergic input from mPOA-VTA efferent decreases and yields disinhibition of DA-producing neurons in the VTA. With this disinhibition, greater levels of DA in the NAc follow cocaine administration.

et al, 2013) and lactating female rats (Lonstein and De Vries, 2000), suggesting that naturally rewarding behaviors are also modulated via GABAergic projections from the mPOA. Finally, inhibition of the mPOA with GABA agonists increases locomotion (Arrati et al, 2006), a behavioral correlate of increased DA release in the NAc (Costall et al, 1984). Our present findings demonstrate substantial apposition between mPOA terminals and TH-ir perikarya of mesolimbic efferents in the VTA. Consequently, when taking previously published work and the present findings into account, we believe it reasonable to propose that mPOA efferents inhibit activity of VTA DA cells via GABAergic projections.

Given the similarity of results between the lesion and E2-microinjection experiments, namely the increased release of cocaine-induced DA, we also propose that estrogen in the mPOA facilitates cocaine-induced DA in the NAc by inhibiting GABAergic output from the mPOA to the VTA. The preponderance of available evidence points in this direction. GABAergic neurons within the mPOA are sensitive to estrogens (Sar et al, 1983). Estrogen increases GABA concentration, the reuptake of GABA, and the expression of $\mathrm{GABA}_{\mathrm{A}}$ receptors within the mPOA (Herbison, 1997). Additionally, studies in the hippocampus have demonstrated that estrogen modulates synaptic plasticity of GABAergic neurons (Naftolin et al, 1996). Estrogen treatment has also been shown to modulate the electrophysiology of GABAergic neurons in the mPOA in a biphasic manner (Wagner et al, 2001). Specifically, estrogen prevents baclofen-induced hyperpolarization before the luteinizing hormone surge, whereas, during the luteinizing hormone surge, estrogen treatment decreases $\mathrm{GAD}_{67}$ immunoreactivity (Wagner et al, 2001).

It is worth noting that subjects who were pretreated with systemic E2 exhibited a greater increase in cocaine-induced DA release $15 \mathrm{~min}$ after cocaine administration. This suggests that, while $\mathrm{E} 2$ regulates cocaine-induced DA release by acting in the mPOA, E2 also facilitates cocaine-induced DA release by acting elsewhere in the brain. These results are not surprising as E2 has been shown to also modulate DA activity within the NAc. Specifically, basal levels of striatal DA vary across the estrous cycle (Becker and $\mathrm{Hu}, 2008$ ). Additionally, ovariectomies attenuate, and E2 restores, amphetamine-induced DA release (Becker and $\mathrm{Hu}, 2008$ ). However, most of the direct effects of E2 on NAc DA activity occur rapidly (within 30 min of E2 administration) (Becker and $\mathrm{Hu}, 2008$ ), whereas the present study found an increased DA response 5 days after the last systemic dose of E2. A significant decrease in circulating sex-steroid hormones following OVX alters synaptic connectivity in other brain regions such as the hippocampus (Day and Good, 2005), increases GFAP-ir, a protein found in astrocytes, in the VTA and prefrontal cortex, but not the NAc, 4 weeks after OVX (Flores et al, 1999). Additionally, ovariectomies decreased the firing rate of VTA DA neurons (Zhang et al, 2008). Thus, it is likely that a 3.5-week absence of $\mathrm{E} 2$ altered the connectivity between the NAc and other estrogen-sensitive brain regions. Finally, subjects treated with systemic E2 before microinjections also exhibited a greater percent change in DA in response to a saline injection; however, this effect was not statistically significant. This trend may suggest that systemic E2 also modulates dopaminergic response to an acute 
stressor. However, to the best of our knowledge, there are no studies examining the interaction between acute stress and E2 administration on accumbal DA levels.

E2 modulates behavior via both rapid molecular cascades and classical long-lasting genomic actions (McEwen and Alves, 1999). Estrogen-sensitive behaviors regulated by hypothalamic nuclei such as eating, drinking, maternal behavior, and female sexual behaviors are typically displayed 1-2 days after E2 administration, suggesting that they are regulated by classical estrogen signaling (Graves et al, 2011; Hull and Dominguez, 2012; Stolzenberg and Numan, 2011). In the present study, we chose to examine cocaine-induced DA release $24 \mathrm{~h}$ after the administration of $\mathrm{E} 2$, as previous literature suggests that feeding behavior is modulated by E2 microinjections into the mPOA $24 \mathrm{~h}$ after injection (Santollo et al, 2011). Additionally, female rats are most sensitive to cocaine on the day of estrus (Sell et al, 2005), hours after the natural estrogen surge (McEwen and Alves, 1999), suggesting that these behavioral changes are modulated, at least in part, by sex-steroid hormone receptors. The present study found colocalization of ER $\alpha$ and mPOA-VTA efferents. However, there was also substantial colocalization of these VTA afferents and cells expressing GPER. While the present results are likely not due to the rapid action of estrogens, it is always possible that estrogens modulate the mPOA through GPER, as well as ER $\alpha$. E2 activation of GPER leads to an increase in protein kinase $\mathrm{C} \delta$ activity, which in turn results in decreased sensitivity of $\mathrm{GABA}_{\mathrm{B}}$ receptors and therefore greater neuronal excitability (Roepke et al, 2009). Since not all mPOA neurons appose TH-ir cells in the VTA, the increased activity of the GPER-containing neurons might be inhibiting GABAergic interneurons in the VTA (van Zessen et al, 2012), thereby disinhibiting dopaminergic output.

Consistent with the present findings, we previously showed (Tobiansky et al, 2013) that the mPOA innervates the VTA in a region-specific manner, and that lesions of the mPOA augmented both cocaine-induced Fos expression in the NAc and cocaine-induced conditioned place preference. We also showed that $\sim 68 \%$ of mPOA-VTA efferents release GABA, over $75 \%$ are sensitive to DA as evidenced by colocalization with DA receptors, and that nearly $60 \%$ of these contain both DA receptors and GABA (Tobiansky et al, 2013).

In this study, we now demonstrate that E2 in the mPOA influences cocaine-induced DA release in the NAc. Our results further indicate that the $\mathrm{mPOA}$ provides inhibitory input to the mesolimbic system, as lesions increased accumbal DA release in response to cocaine, when compared with the sham-lesion animals. Moreover, our data support studies demonstrating E2-mediated enhancement of cocaine response (Evans and Foltin, 2010; Hu et al, 2004; Jackson et al, 2006). Here we also obtained immunohistochemical evidence indicating that this modulation occurs via nuclear and membrane-associated estrogen receptors in VTA afferents from the mPOA. E2 microinjections into the $\mathrm{mPOA}$ also support the idea that estrogen receptors in the $\mathrm{mPOA}$ are influencing activity in VTA afferents and, ultimately, the accumbal DA response to cocaine. These results underline the importance of the mPOA as an integral region involved in the processing of reinforcing stimuli, both natural and drug-related (see Figure 4 for a summary of this model).

\section{FUNDING AND DISCLOSURE}

Funding for the current study was provided by NIDA grant R01-DA032789 to JMD. RGW and KDL are on training grant T32-AA007471. The authors report no biomedical financial interests or potential conflict of interest. Authors DJT and RGW contributed equally to this work.

\section{ACKNOWLEDGMENTS}

We thank Julie Hayes at the Microscopy and Imaging Facility of the Institute for Cellular and Molecular Biology at the University of Texas at Austin for assistance with confocal microscopy. We also thank Dr. Christopher Robison for comments on a later version of the manuscript.

\section{REFERENCES}

Arrati PG, Carmona C, Dominguez G, Beyer C, Rosenblatt JS (2006). GABA receptor agonists in the medial preoptic area and maternal behavior in lactating rats. Physiol Behav 87: 51-65.

Becker JB, Hu M (2008). Sex differences in drug abuse. Front Neuroendocrinol 29: 36-47.

Brailoiu E, Dun SL, Brailoiu GC, Mizuo K, Sklar LA, Oprea TI et al (2007). Distribution and characterization of estrogen receptor G protein-coupled receptor 30 in the rat central nervous system. J Endocrinol 193: 311-321.

Carroll ME, Lynch WJ, Roth ME, Morgan AD, Cosgrove KP (2004). Sex and estrogen influence drug abuse. Trends Pharmacol Sci 25: 273-279.

Costall B, Domeney AM, Naylor RJ (1984). Locomotor hyperactivity caused by dopamine infusion into the nucleus accumbens of rat brain: specificity of action. Psychopharmacology 82: 174-180.

Cummings JA, Jagannathan L, Jackson LR, Becker JB (2014). Sex differences in the effects of estradiol in the nucleus accumbens and striatum on the response to cocaine: neurochemistry and behavior. Drug Alcohol Depend 135: 22-28.

Day M, Good M (2005). Ovariectomy-induced disruption of longterm synaptic depression in the hippocampal CA1 region in vivo is attenuated with chronic estrogen replacement. Neurobiol Learn Mem 83: 13-21.

Di Chiara G, Bassareo V, Fenu S, De Luca MA, Spina L, Cadoni C et al (2004). Dopamine and drug addiction: the nucleus accumbens shell connection. Neuropharmacology 47: 227-241.

Evans SM, Foltin RW (2010). Does the response to cocaine differ as a function of sex or hormonal status in human and non-human primates? Hormones Behav 58: 13-21.

Festa ED, Quinones-Jenab V (2004). Gonadal hormones provide the biological basis for sex differences in behavioral responses to cocaine. Hormones Behav 46: 509-519.

Flores C, Salmaso N, Cain S, Rodaros D, Stewart J (1999). Ovariectomy of adult rats leads to increased expression of astrocytic basic fibroblast growth factor in the ventral tegmental area and in dopaminergic projection regions of the entorhinal and prefrontal cortex. $J$ Neurosci 19: 8665-8673.

Graham MD, Pfaus JG (2013). Infusions of ascorbic acid into the medial preoptic area facilitate appetitive sexual behavior in the female rat. Physiol Behav 122: 140-146.

Graves NS, Hayes H, Fan L, Curtis KS (2011). Time course of behavioral, physiological, and morphological changes after estradiol treatment of ovariectomized rats. Physiol Behav 103: 261-267.

Herbison AE (1997). Estrogen regulation of GABA transmission in rat preoptic area. Brain Res Bull 44: 321-326.

Herbison AE, Augood SJ, McGowan EM (1992). Expression of glutamic acid decarboxylase messenger RNA in rat medial 
preoptic area neurones during the oestrous cycle and after ovariectomy. Brain Res 14: 310-316.

Hu M, Crombag HS, Robinson TE, Becker JB (2004). Biological basis of sex differences in the propensity to self-administer cocaine. Neuropsychopharmacology 29: 81-85.

Hull EM, Dominguez J (2012). Sexual behavior. In: Nelson RJ, Mizumori S (eds). Handbook of Psychology, 2nd edn, Vol 3. Wiley: New York, NY, pp 331-364.

Ikemoto S (2007). Dopamine reward circuitry: two projection systems from the ventral midbrain to the nucleus accumbensolfactory tubercle complex. Brain Res Rev 56: 27-78.

Jackson LR, Robinson TE, Becker JB (2006). Sex differences and hormonal influences on acquisition of cocaine self-administration in rats. Neuropsychopharmacology 31: 129-138.

Koob GF, Volkow ND (2010). Neurocircuitry of addiction. Neuropsychopharmacology 35: 217-238.

Lauber AH, Romano GJ, Pfaff DW (1991). Gene expression for estrogen and progesterone receptor mRNAs in rat brain and possible relations to sexually dimorphic functions. J Steroid Biochem Mol Biol 40: 53-62.

Lonstein JS, De Vries GJ (2000). Maternal behaviour in lactating rats stimulates $c$-fos in glutamate decarboxylase-synthesizing neurons of the medial preoptic area, ventral bed nucleus of the stria terminalis, and ventrocaudal periaqueductal gray. $\mathrm{Neu}$ roscience 100: 557-568.

Lonstein JS, Pereira M, Morrell JI, Marler CA (2015). Parenting behavior. In: Plant TM, Zeleznik AJ (eds). Physiology of Reproduction: New York, pp 2371-2437.

McEwen BS, Alves SE (1999). Estrogen actions in the central nervous system. Endocr Rev 20: 279-307.

McHenry JA, Rubinow DR, Stuber GD (2015). Maternally responsive neurons in the bed nucleus of the stria terminalis and medial preoptic area: putative circuits for regulating anxiety and reward. Front Neuroendocrinol 38: 65-72.

Miller SM, Lonstein JS (2009). Dopaminergic projections to the medial preoptic area of postpartum rats. Neuroscience 159: 1384-1396.

Naftolin F, Leranth C, Horvath TL, Garcia-Segura LM (1996). Potential neuronal mechanisms of estrogen actions in synaptogenesis and synaptic plasticity. Cell Mol Neurobiol 16: 213-223.

Numan M, Smith HG (1984). Maternal behavior in rats: evidence for the involvement of preoptic projections to the ventral tegmental area. Behav Neurosci 98: 712-727.

Pfaus JG, Jones SL, Flanagan-Cato LM, Blaustein JD (2015). Female sexual behavior. In: Plant TM, Zeleznik AJ (eds). Physiology of Reproduction. Elsevier: New York, NY, USA, pp 2287-2370.

Roberts DC, Bennett SA, Vickers GJ (1989). The estrous cycle affects cocaine self-administration on a progressive ratio schedule in rats. Psychopharmacology 98: 408-411.
Roepke TA, Qiu J, Bosch MA, Ronnekleiv OK, Kelly MJ (2009). Cross-talk between membrane-initiated and nuclear-initiated oestrogen signalling in the hypothalamus. J Neuroendocrinol 21: 263-270.

Santollo J, Torregrossa AM, Eckel LA (2011). Estradiol acts in the medial preoptic area, arcuate nucleus, and dorsal raphe nucleus to reduce food intake in ovariectomized rats. Horm Behav 60: 86-93.

Sar M, Stumpf WE, Tappaz ML (1983). Localization of 3H estradiol in preoptic GABA neurons. Fed Proc 42: 495.

Sell SL, Dillon AM, Cunningham KA, Thomas ML (2005). Estrous cycle influence on individual differences in the response to novelty and cocaine in female rats. Behav Brain Res 161: 69-74.

Simerly RB, Swanson LW (1988). Projections of the medial preoptic nucleus: a Phaseolus vulgaris leucoagglutinin anterograde tracttracing study in the rat. J Comp Neurol 270: 209-242.

Stolzenberg DS, Numan M (2011). Hypothalamic interaction with the mesolimbic DA system in the control of the maternal and sexual behaviors in rats. Neurosci Biobehav Rev 35: 826-847.

Tobiansky DJ, Roma PG, Hattori T, Will RG, Nutsch VL, Dominguez JM (2013). The medial preoptic area modulates cocaine-induced activity in female rats. Behav Neurosci 127: 293-302.

Tsuneoka Y, Maruyama T, Yoshida S, Nishimori K, Kato T, Numan M et al (2013). Functional, anatomical, and neurochemical differentiation of medial preoptic area subregions in relation to maternal behavior in the mouse. J Comp Neurol 521: 1633-1663.

van Zessen R, Phillips JL, Budygin EA, Stuber GD (2012). Activation of VTA GABA neurons disrupts reward consumption. Neuron 73: 1184-1194.

Wagner EJ, Ronnekleiv OK, Bosch MA, Kelly MJ (2001). Estrogen biphasically modifies hypothalamic GABAergic function concomitantly with negative and positive control of luteinizing hormone release. J Neurosci 21: 2085-2093.

Zhang D, Yang S, Yang C, Jin G, Zhen X (2008). Estrogen regulates responses of dopamine neurons in the ventral tegmental area to cocaine. Psychopharmacology 199: 625-635.

This work is licensed under a Creative Commons Attribution-NonCommercial-ShareAlike $\quad 4.0$ International License. The images or other third party material in this article are included in the article's Creative Commons license, unless indicated otherwise in the credit line; if the material is not included under the Creative Commons license, users will need to obtain permission from the license holder to reproduce the material. To view a copy of this license, visit http://creativecommons.org/licenses/by-nc-sa/4.0/

Supplementary Information accompanies the paper on the Neuropsychopharmacology website (http://www.nature.com/npp) 